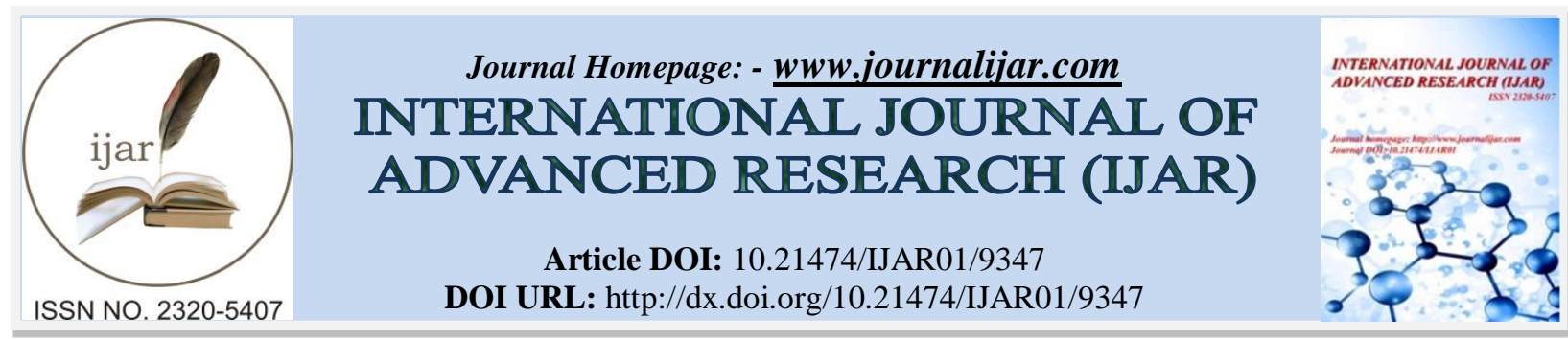

RESEARCH ARTICLE

\title{
GENETIC DIVERGENCE FOR YIELD AND ITS COMPONENTS IN MYANMAR LOCAL RICE (Oryza sativa L.) GERMPLASM
}

"Nyo Mar Htwe ${ }^{1}$ and Chan Nyein Thu" ${ }^{2}$

1. Deputy Director, Advanced Centre for Agricultural Research and Education, Yezin Agricultural University.

2. MSc candidate, Department of Plant Breeding, Physiology and Ecology, Yezin Agricultural University.

\section{Manuscript Info}

Manuscript History

Received: 05 May 2019

Final Accepted: 07 June 2019

Published: July 2019

Key words:-

cluster, genetic diversity, principle component analysis.

\section{Abstract}

The experiment was conducted at the Department of Plant Breeding, Physiology and Ecology field, Yezin Agricultural University in Myanmar, 2017 (dry season) to determine the genetic diversity among forty-two local rice genotypes by using cluster and principle components analysis. The field was laid out in a randomized complete block design with three replications. Genotypes showed highly significant difference for all the traits studied, which suggests that the genotypes constitute a pool of germplasm with adequate genetic variability. Five major groups were observed among 42 local rice genotypes based on multivariate analysis. The genotypes within the Cluster V has highest mean value for yield plant $^{-1}$, spikelet panicle ${ }^{-1}$, filled grain percent, harvest index, panicle/straw weight ratio, panicle weight, effective tiller ${ }^{-1}$, and lowest value of straw weight. Therefore, these genotypes should be selected for potential genotypes used in future breeding programs. The maximum inter cluster distances were observed between cluster II and V followed by cluster I and II. Therefore, crosses involving between cluster $\mathrm{V}$ and cluster II might exhibit high heterosis for yield and crosses between cluster I and II might exhibit higher heterosis for earliness and dwarf stature. The first three principal components explained $81.627 \%$ of the total variations, thus suggesting that traits such as yield per plant, harvest index, panicle/straw weight ratio, panicle weight, filled grain percent, effective tillers hill $^{-1}$ and spikelet panicle ${ }^{-1}$ were the principal discriminatory characteristics. Therefore, the high level of genetic variation and the traits contributing for the variation was identified. Hence these genotypes can be utilized for trait improvement in breeding programs for the traits contributing for major variation.

Copy Right, IJAR, 2019,. All rights reserved.

\section{Introduction:-}

Rice (Oryza sativa L.) is one of the most important cereal crops worldwide. Myanmar is one of the centers of origin of cultivated rice (Chang, 1976; Matsuo and Hoshikawa, 1993). As a potential for export, rice is grown extensively around the country of Myanmar. Myanmar is the world's sixth-largest rice-producing country (Wunna et al., 2016). (Yamanaka et al., 2011) also found that many ethnic groups still maintained their preferred landraces which is 
locally adapted, as a good example of on-farm conservation of genetic diversity in Myanmar. Tun et al. (2006) indicated that the high genetic diversity could be seen in the materials grown on farms in Myanmar.

The germplasm materials are fully characterized and evaluated for their potential use in breeding programs, effective utilization of germplasms can be enhanced. Evaluation of these germplasms is important to assess their potential as donor parents for the breeding of new varieties with resistant to various abiotic and biotic stresses. The success of any plant breeding programmes largely depends on the existence of diversity among the genotypes (Allard, 1960). Success in recombination breeding depends on the suitable exploitation of genotypes as parents for obtaining high heterotic crosses and transgressive segregants. The crosses between parents with maximum genetic divergence are generally the most responsive for genetic improvement (Arunachalam, 1981).

Hybridization programme involving genetically diverse parents belonging to different clusters would provide an opportunity for bringing together gene groups of diverse nature (Ranjith et al., 2018). Inclusion of more diverse parents (within a limit) is believed to increase the chances for obtaining stronger heterosis and gives broad spectrum of variability in segregating generations (Joshi and Dhawan, 1966; Anand and Murty, 1968). In addition, crossing in moderately diverse parents also showed maximum heterosis (Chauhan and Singh, 1982).

The divergence can be studied based on multivariate analysis and grouped into various cluster as given by (Spark, 1973). The necessity of principal component analysis (PCA) for measuring the degree of divergence has been established by several investigators in rice and other crops (De et al., 1988; Selvakumar et al., 1989; Pathan et al., 1993). These are considered as the most effective method for qualifying the degree of genetic diversity among the genotypes included in the study. The quantification of divergence among the biological population and assessing the relative contribution of different components to the total divergence at intra and inter-cluster levels have now become possible. Hence, the present investigation was carried out to determine the genetic diversity among fortytwo local rice genotypes by using cluster and principle components analysis.

\section{Materials and Methods:-}

Forty-two collected rice germplasm was grown in randomized complete block design with three replications at Department of Plant Breeding, Physiology and Ecology field, Yezin Agricultural University, Myanmar in 2017 dry season (Table 1). The spacing was $20 \mathrm{~cm} \times 20 \mathrm{~cm}$ with one seedling per hill was planted. Observations were recorded on five randomly chosen plants of each genotype per replication for agronomical traits. Recommended cultural practices were follows whenever needed to obtain optimum performance. The data on days to flowering (days), plant height $(\mathrm{cm})$, effective tillers hill ${ }^{-1}$ (no.), panicle weight $(\mathrm{g})$, straw weight $(\mathrm{g})$, panicle/straw weight ratio, panicle length $(\mathrm{cm})$, filled grain percent, spikelet panicle ${ }^{-1}$ (no.), 1000 grain weight $(\mathrm{g})$, harvest index, yield plant ${ }^{-1}$ (g) were collected according to the Standard Evaluation System for Rice (SES 2013). Analysis of variance (ANOVA) was carried out on the data to assess the genotypic effects for randomized complete blocks design in STAR 2.0.1 (STAR, 2014). Cluster analysis was done by using XLSTAT. The genotypes were grouped into different clusters by using Gower clustering method. Intra and inter-cluster distances and mean performance of the clusters for the characters were also computed.

Table 1. List of local rice genotypes used for the study

\begin{tabular}{|l|l|l|}
\hline No. & Germplasm & Source \\
\hline 1 & BaKauk & DaWai, YAU collection \\
\hline 2 & BayKyaung & DAR, Seed Bank \\
\hline 3 & GaukRa & DAR, Seed Bank \\
\hline 4 & KalarGyi & Mon, YAU collection \\
\hline 5 & KalarLay & DAR, Seed Bank \\
\hline 6 & KuTaungMyoTun & DAR, Seed Bank \\
\hline 7 & KhaingShweWar & Myeik, YAU collection \\
\hline 8 & KhaoHline & DAR, Seed Bank \\
\hline 9 & KhaoLai & DAR, Seed Bank \\
\hline 10 & KhaoLamil & DAR, Seed Bank \\
\hline 11 & KhaoLan & DAR, Seed Bank \\
\hline 12 & KhaoLin & DAR, Seed Bank \\
\hline 13 & KhaoLiPaw & DAR, Seed Bank \\
\hline
\end{tabular}




\begin{tabular}{|l|l|l|}
\hline 14 & KhaoMaPhut & DAR, Seed Bank \\
\hline 15 & KhaoNyoHon & DAR, Seed Bank \\
\hline 16 & KhaoPhaLin & DAR, Seed Bank \\
\hline 17 & KhaoPiPaung & DAR, Seed Bank \\
\hline 18 & KhaoTan & DAR, Seed Bank \\
\hline 19 & KhaowaA & DAR, Seed Bank \\
\hline 20 & KunLone & DAR, Seed Bank \\
\hline 21 & KyweChaeManaing & DAR, Seed Bank \\
\hline 22 & LawThawGyi & DAR, Seed Bank \\
\hline 23 & LetYoneGyi & DAR, Seed Bank \\
\hline 24 & LetYwesin & DAR, Seed Bank \\
\hline 25 & LopaZa & DAR, Seed Bank \\
\hline 26 & MaeKhalar-5 & DAR, Seed Bank \\
\hline 27 & MaungPhaLo & DAR, Seed Bank \\
\hline 28 & MuyinSaba & DAR, Seed Bank \\
\hline 29 & PaDinThuMa & DAR, Seed Bank \\
\hline 30 & PhoKawGyi & DAR, Seed Bank \\
\hline 31 & PyawtTun & YAU collection \\
\hline 32 & SeinGyi & DAR, Seed Bank \\
\hline 33 & ShweHinThar & DAR, Seed Bank \\
\hline 34 & ShweYinAye & Shan, YAU collection \\
\hline 35 & TaTaungPo & DAR, Seed Bank \\
\hline 36 & TaungAtBeSaba & DAR, Seed Bank \\
\hline 37 & TaungHtakePan & Bago, YAU collection \\
\hline 38 & TaungYarSaba & DAR, Seed Bank \\
\hline 39 & TinTayar & YAU collection \\
\hline 40 & WetSiPhyu & DAR, Seed Bank \\
\hline 41 & YarPyae & YAU collection \\
\hline 42 & YawShweWar & DaWai, YAU collection \\
\hline & & \\
\hline & & \\
\hline
\end{tabular}

\section{Results and Discussion:-}

Analysis of Variance (ANOVA) for agronomic traits of 42 local rice genotypes

The mean squares values due to genotypes were highly significant differences for days to flowering, plant height, effective tillers hill ${ }^{-1}$, panicle weight, straw weight, panicle/straw weight ratio, panicle length, filled grain percent, spikelet panicle $^{-1}, 1000$ grain weight, harvest index and yield plant ${ }^{-1}$ (Table 2). This result indicated that there was the high genetic variability within the genotypes and it would be beneficial for improvement of the crop.

Table 2. Analysis of variance on agronomic traits of 42 local rice genotypes

\begin{tabular}{|l|l|l|l|l|}
\hline Source of variation & Replication & Genotypes & Error & CV \\
\hline Days to flowering & 13.883 & $496.163^{* *}$ & 4.309 & 2.04 \\
\hline Plant height & 4.661 & $1180.33^{* *}$ & 9.377 & 2.40 \\
\hline Effective tillers hill $^{-1}$ & 0.372 & $36.129^{* *}$ & 1.901 & 10.55 \\
\hline Panicle weight & 0.814 & $401.813^{* *}$ & 8.455 & 11.16 \\
\hline Straw weight & 74.563 & $6729.992^{* *}$ & 88.087 & 9.48 \\
\hline Panicle/Straw weight ratio & 0.003 & $0.246^{* *}$ & 0.003 & 14.31 \\
\hline Panicle length & 3.369 & $22.613^{* *}$ & 2.437 & 6.76 \\
\hline Filled grain percent $^{\text {Spikelets panicle }} \mathbf{- 1}^{* *}$ & $1222.443^{* *}$ & 44.659 & 11.10 \\
\hline 1000 grain weight $^{\text {Harvest Index }}$ & 158.030 & $2472.382^{* *}$ & 173.79 & 15.35 \\
\hline Yield plant $^{-1}$ & 474.289 & $43.433^{* *}$ & 0.452 & 2.74 \\
\hline
\end{tabular}

$*$ and $* *$ significant at 0.05 and 0.01 level respectively. 


\section{Cluster Analysis}

Based on the degree of genetic divergence 42 local rice genotypes (Figure $1 \&$ Table 4) were group into five major groups based on multivariate analysis. Cluster V contained the maximum number of genotypes (12). Clusters I, II and IV consisted of eight genotypes. Cluster III consisted of only six genotypes. It could be suggested that hybridization among the genotypes within cluster will not be effective because their genetic content is almost similar. In addition, the genotypes among different clusters could be hybridized to crease a wider genetic variability for yield and other superior traits.

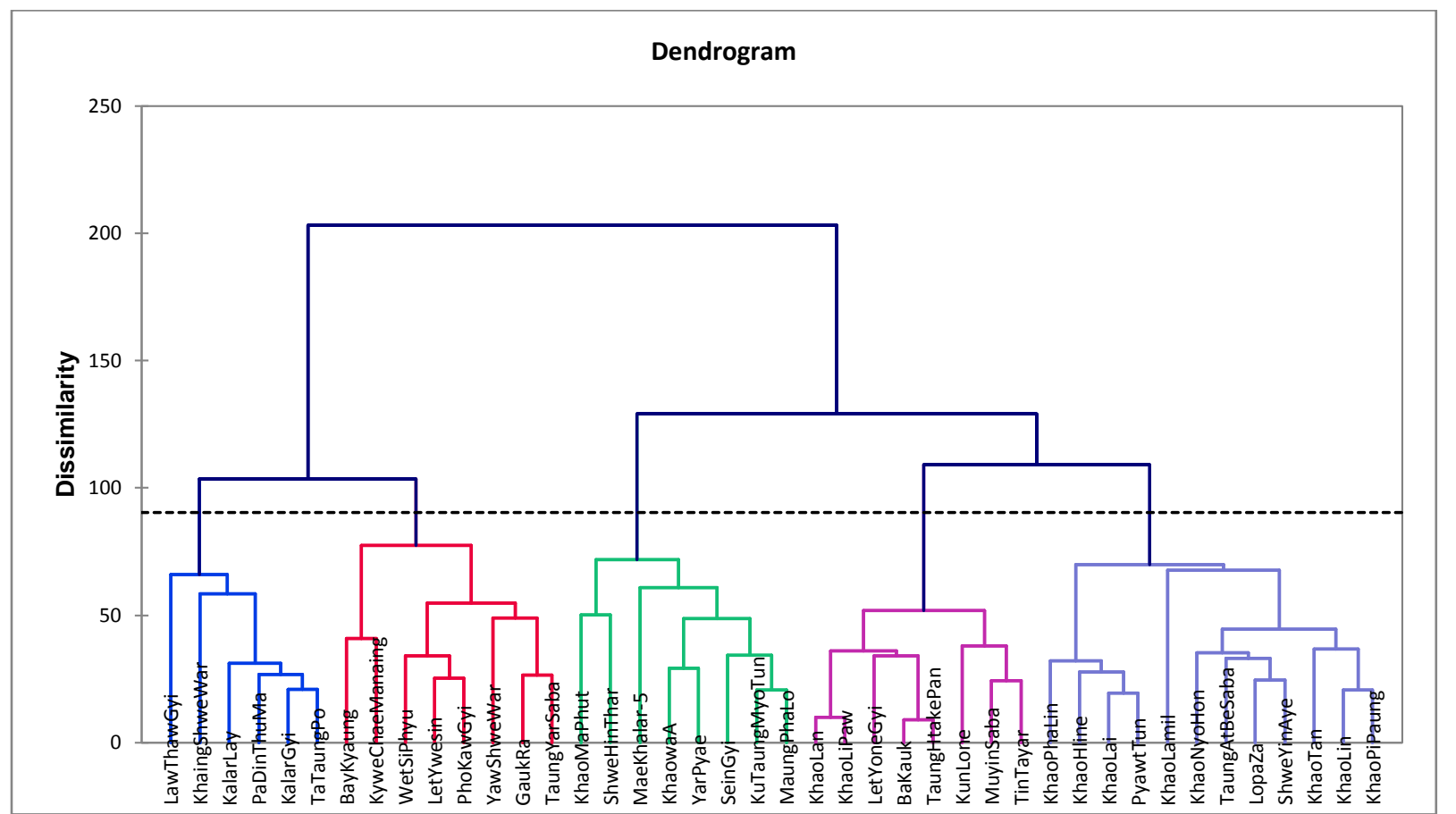

Figure 1. Dendrogram generated by cluster analysis of agronomic characters using complete linkage based on Gower similarity coefficient estimated from 12 agronomic traits analyzed in 42 genotypes

Table 4. Distribution of 42 rice genotypes into different clusters based on 12 agronomic characters

\begin{tabular}{|l|l|l|l|l|}
\hline Cluster I & Cluster II & Cluster III & Cluster IV & Cluster V \\
\hline BaKauk & BayKyaung & KalarGyi & KuTaungMyoTun & KhaoHline \\
\hline KhaoLan & GaukRa & KalarLay & KhaoMaPhut & KhaoLai \\
\hline KhaoLiPaw & KyweChaeManaing & KhaingShweWar & KhaowaA & KhaoLamil \\
\hline KunLone & LetYwesin & LawThawGyi & MaeKhalar-5 & KhaoLin \\
\hline LetYoneGyi & PhoKawGyi & PaDinThuMa & MaungPhaLo & KhaoNyoHon \\
\hline MuyinSaba & TaungYarSaba & TaTaungPo & SeinGyi & KhaoPhaLin \\
\hline TaungHtakePan & WetSiPhyu & & ShweHinThar & KhaoPiPaung \\
\hline TinTayar & YawShweWar & & YarPyae & KhaoTan \\
\hline & & & & LopaZa \\
\hline & & & & PyawtTun \\
\hline & & & & ShweYinAye \\
\hline & & & & TaungAtBeSaba \\
\hline
\end{tabular}

The cluster mean values showed a wide range of variations for all the characters (Table 5). Cluster V exhibited highest mean value for yield plant $^{-1}$, spikelet panicle ${ }^{-1}$, filled grain percent, harvest index, panicle/straw weight ratio, panicle weight, effective tiller ${ }^{-1}$, and lowest value of straw weight. Cluster IV contained genotypes with highest mean value for panicle length and 1000 grain weight. Cluster I recorded lowest value for days to flowering and plant height. These clusters are suggested to provide a broad spectrum of variability and the genotypes present in them may be used as parents for future hybridization programme to develop desirable types and creation of further variability for these characters (Mishra and Pravin, 2004). 
Table 5. Cluster mean of 12 characters for genetic divergence in 42 rice genotypes

\begin{tabular}{|l|l|l|l|l|l|}
\hline & Cluster I & Cluster II & Cluster III & Cluster IV & Cluster V \\
\hline Days to flowering & $\mathbf{8 7 . 5 0 0}$ & 106.104 & 113.611 & 103.583 & 101.222 \\
\hline Plant Height (cm) & $\mathbf{1 1 5 . 9 0 0}$ & 126.844 & 133.617 & 154.441 & 115.124 \\
\hline Effective tillers hill $^{-1}$ & 13.819 & 9.500 & 11.213 & 13.443 & $\mathbf{1 5 . 6 6 2}$ \\
\hline Panicle Weight & 23.248 & 13.165 & 15.545 & 31.557 & $\mathbf{3 8 . 1 1 8}$ \\
\hline Straw Weight & 61.796 & 169.265 & 136.247 & 106.356 & $\mathbf{5 3 . 4 0 1}$ \\
\hline Panicle/Straw weight ratio & 0.400 & 0.079 & 0.116 & 0.306 & $\mathbf{0 . 7 4 2}$ \\
\hline Harvest Index & 0.279 & 0.072 & 0.103 & 0.230 & $\mathbf{0 . 4 1 9}$ \\
\hline Panicle Length & 20.355 & 23.945 & 23.518 & $\mathbf{2 4 . 7 0 6}$ & 23.064 \\
\hline Filled grain percent (\%) & 67.533 & 42.949 & 36.233 & 62.713 & $\mathbf{7 7 . 0 9 1}$ \\
\hline Spikelet panicle & 75.357 & 45.878 & 78.824 & 98.454 & $\mathbf{1 1 4 . 7 5 0}$ \\
\hline 1000 grains weight & 23.422 & 25.029 & 23.903 & $\mathbf{2 7 . 9 1 3}$ & 23.064 \\
\hline Yield plant $^{-1}$ & 16.498 & 4.618 & 7.794 & 22.884 & $\mathbf{3 0 . 9 9 1}$ \\
\hline Average intra
\end{tabular}

Average intra and inter-cluster distances have been shown in Table 6. The highest intra-cluster distance was observed in cluster IV (30.860) followed by cluster II (30.826) and cluster V (29.832) indicating wide genetic diversity among the genotypes belonging to these clusters. Therefore, genotypes from these clusters should be given attention for selection of parents for hybridization programme because most of the elite breeding cultivars were included in this cluster. The minimum intra-cluster distance was observed in clusters I and III. Crossing the genotypes of the same cluster showing low values for intra-cluster distance may be low to get good segregants. Therefore, the crosses should be made between the genotypes of clusters separated by large inter-cluster distances (Chandra et al., 2007; Sandhyakishore et al., 2007).

Highest inter-cluster distance was observed between clusters II and V (144.416) suggesting high divergence of genotypes included in these two clusters. Therefore, genotypes belonging to these clusters may be used in hybridization programme for the improvement of rice. Second largest inter-cluster distance was found between cluster I and II. The least inter-cluster distance was observed between clusters II and III (48.405) followed by clusters III and IV (54.362) indicating close relationship between the genotypes of these clusters and hence, may not be emphasized upon to be used in hybridization programme. According to Rahman et al. (1997), crossing between highly divergent genotypes would produce a broad spectrum of variability enabling further selection and improvement. Thus, selection of genotypes from these clusters for a crossing programme will produce desirable transgressive segregants. The greater the distance between two clusters the wider the genetic diversity between their genotypes. Therefore, the genotypes from the clusters having maximum inter-cluster distance can be selected to yield superior segregants (Mishra et al., 2003; Chaturvedi and Maurya, 2005). In this study, genotypes from cluster I, II and V can be selected for crossing programme to get desirable transgressive segregants.

Table 6. Intra (diagonal) and inter cluster average distance in rice genotypes

\begin{tabular}{|l|l|l|l|l|l|}
\hline & Cluster I & Cluster II & Cluster III & Cluster IV & Cluster V \\
\hline Cluster I & $\mathbf{2 5 . 8 2 1}$ & 117.328 & 87.650 & 66.599 & 48.421 \\
\hline Cluster II & & $\mathbf{3 0 . 8 2 6}$ & 48.405 & 92.611 & 144.416 \\
\hline Cluster III & & & $\mathbf{2 6 . 2 9 8}$ & 54.962 & 106.713 \\
\hline Cluster IV & & & & $\mathbf{3 0 . 8 6 0}$ & 70.484 \\
\hline Cluster V & & & & & $\mathbf{2 9 . 8 3 2}$ \\
\hline
\end{tabular}

\section{Principal Component Analysis}

Principal component analysis was done to identify the minimum number of components, which can explain maximum variability out of the total variability (Anderson, 1972; Morrison, 1978). It can be also used to determine and identify the selection criteria and also to rank genotypes on the basis of PC scores. The result of PCA explained the genetic diversity among the rice accessions. According to Brejda et al., (2000), the PCA with eigen values $>1$ and which explained at least $5 \%$ of the variation in the data were considered. The PC with higher eigen values and variables, which had high factor loading were considered as best attributes in principal components.

In this study eigen value of $>1$ found in 3 components and showed cumulative variation of $81.627 \%$ to the total variation. Its indicated that the identified characters within these components exhibited immerse influence on the phenotype. The first principle component accounted for $55.596 \%$ of the total variation in the rice genotypes (Table 
7). Harvest index (0.965) contributed highest to the variation followed by yield per plant (0.939), panicle/straw weight ratio (0.937), panicle weight (0.917), filled grain percent $(0.844)$, effective tillers hill ${ }^{-1}(0.819)$, spikelet panicle $^{-1}(0.782)$. All other characters contributed negatively to the first component. Second principle component contributed $15.387 \%$ of the total variation. Characters that contributed to the component include all characters except filled grain percent that are negatively contributed. The third principle component accounted for $10.644 \%$ of the total variation and 1000 grains weight, plant height, harvest index, filled grain percent, panicle/straw weight ratio contributed positively.

Therefore, PCA revealed principle discriminatory characteristics such as yield plant ${ }^{-1}$, harvest index, panicle/straw weight ratio, panicle weight, filled grain percent, effective tillers hill ${ }^{-1}$ and spikelet panicle ${ }^{-1}$, in diverse PCs which are responsible for the observed genotypic variation within a group of genotypes. Important characters coming together in different PCs have tendency to remain together, which may be kept into consideration during utilization of these characters in breeding programme to bring about rapid improvement for yield and other associated traits. Such result indicated that these seven characters contributed maximum towards divergence. It is interesting that the greater divergence in the materials under study was due to these seven characters, which will offer a good scope for improvement of yield through rational selection of parents.

Table 7. Eigen value, contribution of variability and factor loading for the principal component axis in rice genotypes

\begin{tabular}{|c|c|c|c|c|c|}
\hline & F1 & F2 & F3 & $\mathrm{F} 4$ & F5 \\
\hline Eigenvalue & 6.671 & 1.846 & 1.277 & 0.625 & 0.548 \\
\hline Variability (\%) & 55.596 & 15.387 & 10.644 & 5.210 & 4.570 \\
\hline Cumulative $\%$ & 55.596 & 70.982 & 81.627 & 86.836 & 91.407 \\
\hline & & \multicolumn{4}{|c|}{ Factor loadings value } \\
\hline Days to flowering & -0.295 & 0.507 & -0.646 & -0.426 & -0.134 \\
\hline Plant Height $(\mathrm{cm})$ & -0.430 & 0.731 & 0.233 & -0.163 & 0.305 \\
\hline Effective tillers hill $^{-1}$ & 0.819 & 0.036 & -0.203 & 0.142 & 0.279 \\
\hline Panicle Weight & 0.917 & 0.329 & -0.100 & 0.023 & 0.109 \\
\hline Straw Weight & -0.856 & 0.113 & -0.299 & 0.078 & 0.227 \\
\hline Panicle/Straw weight ratio & 0.937 & 0.008 & 0.055 & -0.041 & -0.230 \\
\hline Harvest Index & 0.965 & 0.044 & 0.111 & -0.030 & -0.165 \\
\hline Panicle Length & -0.255 & 0.746 & -0.018 & 0.577 & -0.161 \\
\hline Filled grain percent $(\%)$ & 0.844 & -0.083 & 0.109 & -0.038 & 0.359 \\
\hline Spikelet panicle $^{-1}$ & 0.782 & 0.390 & -0.118 & -0.071 & -0.197 \\
\hline 1000 grains weight & -0.275 & 0.385 & 0.789 & -0.218 & -0.065 \\
\hline Yield plant $^{-1}$ & 0.939 & 0.256 & -0.038 & -0.026 & 0.133 \\
\hline
\end{tabular}

\section{Conclusions:-}

The agronomic performance of the rice genotypes showed the highly significant differences among the genotypes in respect to all the traits. This indicates that the genotypes constitute a pool of germplasm with adequate genetic variability. Five major groups were observed among 42 local rice genotypes based on multivariate analysis. Cluster $\mathrm{V}$ was the largest containing 12 genotypes followed by cluster I, II and IV with 8 genotypes each. The genotypes within the Cluster V has highest mean value for yield plant $^{-1}$, spikelet panicle ${ }^{-1}$, filled grain percent, harvest index, panicle/straw weight ratio, panicle weight, effective tiller ${ }^{-1}$, and lowest value of straw weight. Therefore, these genotypes should be selected for potential genotypes used in future breeding programs.

The maximum distances were observed between cluster II and V. Thereby, considering yield plant ${ }^{-1}$, spikelet panicle $^{-1}$, filled grain percent, harvest index, panicle/straw weight ratio, panicle weight, effective tiller ${ }^{-1}$, crosses involving cluster V and cluster II might exhibit high heterosis for yield. Again, considering growth duration, and plant height, crosses between cluster I and II might exhibit higher heterosis for earliness and dwarf stature. Therefore, the genotypes under cluster I and cluster II, cluster II and cluster V might be selected for future breeding program.

The results of PCA revealed that the three principal components explained $81.627 \%$ of the total variations, thus suggesting that traits such as yield per plant, harvest index, panicle/straw weight ratio, panicle weight, filled grain 
percent, effective tillers hill ${ }^{-1}$ and spikelet panicle ${ }^{-1}$ were the principal discriminatory characteristics. Therefore, the important characters coming collectively in various PCs and contributing towards explaining the variability and have the tendency to remain together this may be kept into consideration during utilization of these traits in breeding program.

\section{Acknowledgement:-}

This research was financially supported byYAU-JICA Technical Cooperation Project.

\section{References:-}

1. Allard, I. (1960). Principles of Plant Breeding, Chapter 6 through Chapter 9, University of California, Davis. California, John Wiley \& Sons, New York.

2. Anand, I., Murty, B. (1968). Genetic divergence and hybrid performance in linseed. Indian journal of genetics and plant breeding.

3. Anderson, T. (1972). An Introduction to Multivariate Analysis. Wiley Eastem Pvt. Ltd. , New Delhi

4. Arunachalam, V., 1981. Genetic distance in plant breeding. Indian Journal of Genetics and Plant Breeding (The) 41, 226-236.

5. Brejda, J., Moorman, T., Karlen, D., Dao, T. (2000). Identification of regional soil quality factors and indicators. I. Central and Southern High- Plains. Soil Sci. Soc. Am. J. 64, 2115-2124.

6. Chandra, B.S., Reddy, T.D., Ansari, N.A. (2007). Genetic divergence in rice (Oryza sativa L.) Res. Crops 8, 600603.

7. Chang, T.-T. (1976). The origin, evolution, cultivation, dissemination, and diversification of Asian and African rices. Euphytica 25, 425-441.

8. Chaturvedi, H., Maurya, D. (2005). Genetic divergence analysis in rice (Oryza sativa L.). Adv. Plant Sci. 18, 349353.

9. Chauhan, V., Singh, B. (1982). Heterosis and genetic variability in relation to genetic divergence in soybean. Indian Journal of Genetics and Plant Breeding (The) 42, 324-328.

10. De, R., Seetharaman, R., Sinha, M., Banerjee, S. (1988). Genetic divergence in rice. The Indian Journal of Genetics and Plant Breeding 48, 189-194.

11. Joshi, A., Dhawan, N. (1966). Genetic improvement in yield with special reference to self-fertilizing crops. Indian Journal of Genetics and Plant Breeding. Indian sco. Gne Plant Indian Agriculture Res Inst, New Delhi Delhi-110012, India, pp. 101.

12. Matsuo, T., Hoshikawa, K. (1993). Science of the rice plant. Food and Agriculture Policy Research Center Tokyo.

13. Mishra, L., Pravin, J. (2004). Variability and genetic diversity in rice (Oryza sativa L.). Mysore J. Agric. Sci 38, 367 375 .

14. Mishra, L., Sarawgi, A., Mishra, R. (2003). Genetic diversity for morphological and quality traits in rice (Oryza sativa L.) Adv. Plant Sci. 16, 287-293.

15. Morrison, D. (1978). Multivariate Statistical Methods McGraw Hill Kogakusta Ltd.

16. Pathan, M., Haque, E., Miah, N., Miah, M. (1993). Genetic diversity in rice varieties released and recommended by BRRI. Bangladesh Journal of Botany 22, 161-166.

17. Rahman, M., Acharya, B., Sukla, S., Pande, K. (1997). Genetic divergence in low land rice genotypes. Oryza 34, 209212.

18. Ranjith, P., Sahu, S., Dash, S., Bastia, D., Pradhan, B. (2018). Genetic diversity studies in Rice (Oryza sativa L.). Journal of Pharmacognosy and Phytochemistry 7, 2529-2531.

19. Sandhyakishore, N., Babu, V., Ansari, N. (2007). Genetic divergence analysis using yield and quality traits in rice (Oryza sativa L.). Crop Improvement-India 34, 12.

20. Selvakumar, K.S., Soundrapandian, G., Amirthadevarathinam, A. (1989). Genetic divergence for yield and yield components in cold tolerant rice. Madras Agricultural Journal 76 688-694.

21. Spark, D. (1973). Euclidean cluster analysis algorithm. Applied Statistics 22, 126-130.

22. STAR, v. (2014). Biometrics and Breeding Informatics, PBGB Division, International Rice Research Institute, Los Baños, Laguna.

23. Tun, Y.T., Irie, K., Sein, T., Shirata, K., Toyohara, H., Kikuchi, F., Fujimaki, H. (2006). Diverse utilization of Myanmar rice with varied amylose contents. Japanese Journal of Tropical Agriculture 50, 42-50.

24. Wunna, Watanabe, K.N., Ohsawa, R., Obara, M., Yanagihara, S., Aung, P.P., Fukuta, Y. (2016). Genetic variation of rice (Oryza sativa L.) germplasm in Myanmar based on genomic compositions of DNA markers. Breeding science 66, 762-767.

25. Yamanaka, S., Jatoi, S.A., San-Yi, S., Kothari, S.L., Htut, T., Watanabe, K.N. (2011). Genetic diversity of Myanmar rice and their implementation on management methods. African Journal of Biotechnology 10, 1290-1298. 